\title{
O CONCEITO DE JUSTIÇA OCUPACIONAL E AS NUANCES COM A INTERDISCIPLINARIDADE: UM RELATO DE EXPERIÊNCIA
}

\section{Ligia Zorzi Gomes ${ }^{1}$; Daiara Machado da Silva²; Karla Luana Ávila de Borba3; Verônica Bidigaray Sanches ${ }^{4}$; Cristiane Wagner ${ }^{5}$}

\section{RESUMO}

Este relato de experiência tem como objetivo trazer as relações existentes entre o conceito de justiça ocupacional e interdisciplinaridade, para isto foi realizado um estudo entre diários de campo e bibliografia de referência sobre os temas e a partir disso foi estruturado um relato de experiência provindo de uma vivência por residentes em um Centro de Atenção Psicossocial Infanto Juvenil (CAPSI). Observou-se que apesar do conceito de justiça ocupacional ser estruturado pensado no campo terapia ocupacional há uma relação do mesmo com a interprofissionalidade, constatando-se neste relato que todas ações relacionadas à promoção de justiça ocupacional estavam alicerçadas em um atendimento interprofissional, trazendo o dispositivo projeto terapêutico singular como uma ferramenta capaz de ser consonante com a redução de estados de injustiças ocupacional. Não se entende neste relato a importância de concluir uma verdade, assim, ao invés de concluir, entende-se que há nuances entre a promoção de justiça ocupacional e o trabalho cotidiano em um CAPS Infanto Juvenil, observando que o acompanhamento integral de uma criança ou adolescente requer uma articulação entre todas esferas de suas vidas, e assim, a redução de injustiças ocupacionais vêm como requisitos a uma vivência saudável da infância e adolescência.

Palavras-chave: Terapia Ocupacional; Interdisciplinar; Residência Multiprofissional.

Eixo Temático: Atenção Integral e Promoção à Saúde.

\section{INTRODUÇÃO}

Este breve relato de experiência tem como objetivo geral buscar trazer as relações existentes entre o conceito de justiça ocupacional e interdisciplinaridade, com base em uma atuação interdisciplinar por residentes de um programa de residência multiprofissional em saúde mental no interior do estado do Rio Grande do Sul em um serviço que compõe a rede de atenção psicossocial (RAPS). Se percebe a relevância

\footnotetext{
1 Terapeuta Ocupacional - Residente em Saúde Mental - UFN ligia.zorzi@ufn.edu.br

2 Farmacêutica - Residente em Saúde Mental - UFN daiara.machado@ufn.br

${ }^{3}$ Psicóloga - Residente em Saúde Mental - UFN karla.avila@ufn.edu.br

${ }^{4}$ Assistente Social - Residente em Saúde Mental - UFN veronica.sanches@ufn.edu.br

5 Orientadora - Tutora da Residência Multiprofissional - UFN cristiane.wagner@ufn.edu.br
} 
de abordar questões relativas à justiça ocupacional em serviços com foco na saúde mental da população e a aposta na necessidade de um olhar além do atendimento clínico uni-profissional, uma vez que o estabelecimento e os ganhos em programas de residência multiprofissional em saúde é a potencialidade do trabalho interdisciplinar e da troca de saberes. Outro objetivo deste estudo é abordar e relatar vivências vindas do programa de residência multiprofissional sendo que é revelado via estudo haver poucas publicações acerca destas por residentes durante o programa (SILVA; ARAUJO, 2019).

Antes de se buscar uma determinação do que é a justiça ocupacional é necessário compreender alguns engendramentos entre a vida cotidiana, ocupações e a saúde, começando pela perspectiva dos determinantes sociais de saúde previstos na lei 8080, que traz no Art. 3o da Lei no 8080, de 19 de setembro de 1990 que

Art. 3o Os níveis de saúde expressam a organização social e econômica do País, tendo a saúde como determinantes e condicionantes, entre outros, a alimentação, a moradia, o saneamento básico, o meio ambiente, o trabalho, a renda, a educação, a atividade física, o transporte, o lazer e o acesso aos bens e serviços essenciais (BRASIL, 1990).

É possível relacionar estes determinantes ao impacto direto sobre a saúde da população, o que torna a compreensão de saúde de um indivíduo algo muito mais amplo e complexo do que estar ou não doente, uma vez que ter saúde depende de uma série de decisões que fogem do poder individual, perpassando por esferas de poder políticos e governamentais. Assim, quando os determinantes sociais de saúde não são valorizados em uma sociedade, se lida com uma população sem condições de acesso a requisitos básicos para dignidade humana.

O despertar global para a participação restrita, a cidadania limitada e a exclusão social, mais para alguns do que para outros, é congruente com o despertar para a injustiça ocupacional nos campos da ciência ocupacional e da terapia ocupacional (TOWNSEND; MARVAL, 2013, p.231).

A partir desta perspectiva é possível adentrar ao significado do termo justiça ocupacional para a terapia ocupacional, nascido dos estudos da ciência ocupacional, ele provém de uma constatação da injustiça ocupacional, onde como referenciado anteriormente, a participação, cidadania e inclusão social são restritas ou inexistentes para determinados grupos. Justiça ocupacional e injustiça ocupacional se referem a entendimentos sobre situações, condições, esferas que restringem a vida cotidiana e 
a cidadania, impossibilitando sujeitos de serem através da ocupação (TOWNSEND; MARVAL, 2013).

Após breve contextualização sobre a noção de justiça ocupacional se estende a importância de abordar também a experiência multiprofissional suscitada pelos programas de residências multiprofissionais em saúde. As residências multiprofissionais e em área profissional na saúde são criadas a partir da promulgação da Lei no 11.119 de 2005, sendo orientadas pelo Sistema Único de Saúde (SUS).

Art. 13. Fica instituída a Residência em Área Profissional da Saúde, definida como modalidade de ensino de pós-graduação lato sensu, voltada para a educação em serviço e destinada às categorias profissionais que integram a área de saúde, excetuada a médica (BRASIL, 2005).

Vindas com intuito de reorganizar os serviços públicos fortalecendo os princípios e diretrizes norteadores do SUS, é um programa que contribui para a constante renovação e potencialização dos espaços de trabalho, promovendo também uma circulação de residentes com potencial para ampliação de discussões dos processos de trabalho e dos processos institucionais envolvidos nos serviços que compõem o SUS. Cinthia Alves da Silva e Maristela Dalbello-Araujo (2019) abordam em seu estudo a competência deste programa para a efetivação do princípio da integralidade com as conclusões a seguir:

O PRMS ousa, ao dar importante contribuição no sentido de integrar saberes, possibilitar a vivência nos diferentes serviços que compõem a rede de atenção à saúde e contribuir para criar espaços facilitadores das reflexões sobre prática profissional, relações institucionais, interpessoais e com os usuários. O que se pretende é promover mudanças na atenção à saúde, buscando a integralidade das ações prestadas em acordo com uma política de educação permanente para a formação de trabalhadores para o SUS (SILVA; ARAUJO, 2019, p.1242).

O foco em uma aprendizagem interdisciplinar está alicerçado nos princípios que norteiam a Política Nacional de Educação Permanente em Saúde, a qual fomenta as residências multiprofissionais em saúde, compreende-se assim todo o processo como uma formação de sujeito críticos e reflexivos com a realidade de trabalho onde se inserem, capazes de trocas com os trabalhadores que também são vistos sob uma ótica de problematizadores dos processos de trabalho (MAROJA; JÚNIOR; NORONHA, 2020). 
Neste sentido serão abordados neste artigo a importância da realidade interprofissional vinda do programa de residência para uma atuação coerente com a busca por justiça ocupacional e coerente com os princípios do SUS, se valendo de uma vivência entre residentes da terapia ocupacional, da psicologia, da farmácia e do serviço social, que puderam experienciar as potencialidades da interprofissionalidade e de um olhar ampliado aos usuários acompanhados.

\section{METODOLOGIA}

Esta pesquisa consiste em um relato de experiência sobre a atuação interdisciplinar e seus desdobramentos com as questões relativas à justiça ocupacional, no qual se buscou explanar vivências das situações acompanhadas por residentes do programa de residência multiprofissional em saúde mental e relacionálas com suporte teórico sobre os conceitos de justiça ocupacional e trabalho interdisciplinar. Este estudo foi realizado em um Centro de Atenção Psicossocial Infanto Juvenil do interior do estado do Rio Grande do Sul.

O estudo utilizou além de suporte teórico sobre o tema, diários de campo, para engendramento e reflexão sobre as vivências. O diário de campo é uma ferramenta de extrema relevância para análise das intervenções realizados no campo, com grande potencial reflexivo e indagador, uma vez que:

Enquanto forma de documentação profissional articulada ao aprofundamento teórico, o diário de campo, quando utilizado em um processo constante, pode contribuir para evidenciar as categorias emergentes do trabalho profissional, permitindo a realização de análises mais aprofundadas (LIMA, et al., 2007, p.97).

Após análise dos diários de campo e discussão autorreflexiva sobre as situações analisadas, as residentes localizaram o material dos diários de campo aos referenciais teóricos sobre o tema, suscitando os resultados e discussões deste presente estudo.

\section{RESULTADOS E DISCUSSÕES}

Este estudo não busca caracterizar e enquadrar a população atendida em um Centro de Atenção Psicossocial Infanto Juvenil, porém a partir do vivenciado no dia a dia do cotidiano de trabalho é nítido que há boa parte da população atendida, crianças, 
adolescentes e suas famílias, em situações de vulnerabilidade socioeconômica, quadro que foi agravado com as consequências sociais da pandemia de COVID-19 que assola a população mundial desde o ano de 2019, em um estudo realizado no estado do Rio Grande do Sul observou-se que a diminuição da renda familiar era um fator de risco para a saúde mental, destacando que fatores econômicos e sociais exigem uma atenção especial neste período onde a sociedade vivencia uma situação pandêmica (DUARTE, et al. 2020).

$O$ atendimento em um CAPS Infanto Juvenil requer um acompanhamento integral de quem chega ao serviço, ou seja, foge da lógica fragmentada suscitada por modelos de assistência biomédicos, uma que vez que para se oferecer um atendimento integral em saúde mental é necessário levar em consideração a complexidade que envolve o processo de adoecer, ambientado em muito mais que algo biológico, mas emaranhado em uma gama de situações sociais, econômicas, afetivas, ambientais, institucionais, políticas, familiares, entre muitas outras que compõem a vida de uma criança ou adolescente (BRASIL, 2001). Desta forma é pouco provável realizar um acompanhamento integral de uma criança ou adolescente e sua família sem uma equipe interprofissional que compartilhe este atendimento por uma via interdisciplinar, onde se localiza a Residência multiprofissional em Saúde um dispositivo de educação permanente muito eficaz para o desempenho da interdisciplinaridade dentro dos serviços constitutivos da rede de atenção à saúde mental (CERVO, et al.2020).

Surge neste momento a indagação do que tem haver justiça ocupacional com acompanhamento de crianças e adolescentes em um CAPS Infanto Juvenil? Nem de perto é uma pergunta simples de responder, uma vez que não há uma resposta objetiva e nem que sacie essa indagação por completo. O conceito de justiça ocupacional é relativamente novo e ainda pouco estudado no meio científico brasileiro, quiçá discutido nos campos de trabalho, porém, uma das questões que permeiam este conceito é o acesso diferenciado à recursos e vivências, reconhecendo as diferenças existentes entres os sujeitos, e compreendendo que somente dar acesso igualitário não tem o poder de suprir as demandas dos sujeitos (TOWNSEND; MARVAL, 2013). Em consonância com a narrativa que se vivencia diariamente no CAPS Infanto Juvenil deste estudo, cada criança ou adolescente que cruza o caminho deste serviço tem 
uma história de vida única, sendo cada sujeito singular, pensar em um acompanhamento igualitário não está de acordo com a singularidade de cada criança e adolescente acompanhado, assim se pontua um acolhimento diferenciado sob o viés equitativo

O conceito mundial de justiça ocupacional é entendido como:

[...] access to and participation in the full range of meaningful and enriching occupations afforded to others, including opportunities social inclusion and the resources to participate in occupations to satisfy personal, health, and societal needs (American Occupational Therapy Association, 2020, p.79)

Dentro desta visão geral, se encontram estados de injustiça ocupacional, que se diferem entre desequilíbrio ocupacional, privação ocupacional, marginalização ocupacional e alienação ocupacional (STADNYK; TOWNSEND; WILCOCK, 2010). Todavia estes conceitos ainda são novidades nos campos de estudos sobre saúde e assistência a nível nacional, e isto somado ao fato de ser uma discussão ainda restrita a profissão terapia ocupacional acaba por se tornar um assunto não discutido, o que leva este estudo a uma busca pela relação geral entre justiça ocupacional e a importância da interdisciplinaridade, não adentrando nos estados de injustiça ocupacional.

Mesmo que não haja a nomeação do que se vê de vivências de injustiça ocupacional em um CAPS Infanto Juvenil é notável que a equipe interprofissional inclui em suas práticas de trabalho cotidiano ferramentas que auxiliam na luta contra estas injustiças, ou seja, que promovam a justiça ocupacional. Em consonância com o estudo de Elizabeth Townsend e Rebecca Marval (2013), no serviço que abarca este relato de experiência observa-se práticas que estimulam e potencializam o desenvolvimento de capacidades, mudança social e desenvolvimento comunitário, como, por exemplo, oficinas relacionadas à inserção no mercado de trabalho de adolescentes acompanhados no CAPS Infanto Juvenil, acompanhamento integral e longitudinal familiar, oficinas que influenciam no empoderamento das crianças e adolescentes e deem componentes necessários a uma visão crítica e reflexiva sobre o meio em que vivem.

Visto estes pequenos exemplos sobre práticas com potencial de promover a justiça ocupacional é notável a importância de um trabalho interdisciplinar, já que mesmo havendo uma apropriação maior sobre o tema pela terapia ocupacional, a 
questão central dentro dos enlaces da injustiça ocupacional, os cenários de conflito social, perpassa por diversas profissões, e o mais importante, se engendram na dimensão da realidade social e cotidiana dos sujeitos, precisando ser enfrentadas com a integração dos saberes (CÓRDOBA, 2020).

Elizabeth Townsend e Rebecca Marval (2013) indagam em seu estudo acerca da justiça ocupacional se é possível que profissionais promovam esta, a resposta se baseia em várias nuances contraditórias, uma vez que de um lado há grande possibilidade de ao se tentar promover justiça ocupacional que os profissionais acabem por reproduzir uma organização social pautada em relações de poder que incialmente se buscava mudar, e por outro lado, se nota que a justiça ocupacional têm caminhos a ser promovida, como o mesmo estudo menciona:

[...] com uma guinada radical para usar o poder profissional nas práticas sociais que visam reduzir a marginalidade, a exclusão, o apartheid, a desfiliação, a vulnerabilidade e a privação (TOWNSEND; MARVAL, 2013, p. 236, apud GALHEIGO, 2011).

Compreende-se que a associação entre uma prática pautada na interdisciplinaridade e uma visão política sobre as consequências de seu trabalho em um CAPS Infanto Juvenil são alicerces para uma aproximação da promoção de justiça ocupacional, o que requer uma organização institucional baseada em discussões e constantes trocas entre os profissionais a fim de que os mesmos compreendam as relações de poder implicadas em suas práticas.

O projeto terapêutico singulares (PTS) é um dispositivo utilizado no CAPS Infanto Juvenil deste relato que indiretamente se relaciona com a promoção de justiça ocupacional sob uma atuação integral e interprofissional, baseado no modelo de atenção psicossocial onde há a valorização do saber, da singularidade e da autonomia dos usuários de serviços de saúde mental, o PTS tem intuito de promover uma vinculação e corresponsabilização entre equipe e usuário, no caso de uma CAPS Infanto Juvenil, entre equipe, criança ou adolescente e família (SILVA, J et al., 2019). Como o próprio nome já revela se trata de um projeto sobre o andamento do acompanhamento e da vivência desta criança e desse adolescente no serviço de saúde mental, por ser construído conjuntamente como todos atores envolvidos ele possui grande potencial para promoção de aspectos relacionados à justiça ocupacional, dentre, há a importância de citar alguns objetivos já co-construídos no 
CAPS Infanto Juvenil deste estudo: auxílio na confecção de registro geral; articulações em rede de saúde municipal para matrícula escolar de crianças assistidas e outras que compõem rede familiar; auxílio na busca por direitos relativos a gratuidade do transporte público e de medicações; grupo de empoderamento de mães e pais; assembleias comportando as famílias dos usuários acompanhados. Dentre essas ações citadas, uma pequena parte do que se produz cotidianamente, se observa que estes objetivos co-construídos estão de acordo com a promoção de justiça ocupacional, como observado por Pieres e Craik (2004):

[..] devem se concentrar em superar os fatores extrínsecos que dificultam a participação em atividades de lazer, tais como dificuldades de transporte e limitações financeiras, permitindo a socialização e a formação de uma rede de relacionamentos (PIERIS; CRAIK, 2004, p. 246).

Este acompanhamento e estas ações não correspondem exclusivamente a um conceito de justiça ocupacional, longe disso, elas perpassam por uma história de nomeações e conceitos vindos da sociedade, porém como um dos intuitos deste relato é trazer para o cerne das discussões brasileiras um pouco mais sobre a justiça e injustiça ocupacional se explica o enfoque quase específico.

A atuação interprofissional pode ser um dos principais alicerces para que se chegue a estados de combate a injustiças ocupacionais, sendo um conceito da terapia ocupacional (TOWSEND; MARVAL, 2013), a defesa é de que se compreenda que um terapeuta ocupacional não atua sozinho dentro de um CAPS Infanto Juvenil, pois o acompanhamento previsto pelo modelo de assistência psicossocial requer a interprofissionalidade para resolução cotidiana, assim mesmo que seja o terapeuta ocupacional que utilize o conceito de busca por justiça ocupacional, a sua promoção vai depender de toda esfera que compõe a rede de atenção psicossocial.

A atenção em saúde mental é um ciclo constante, e neste ciclo uma das buscas pode ser o estado de justiça ocupacional, que irá depender de muitas etapas anteriores, por exemplo, para que uma criança possa desfrutar de seu papel ocupacional de brincar ela antes precisa ter acesso a alimentação, higiene, saneamento básico, locomoção, moradia, ou seja, há um trabalho árduo entre todos atores da sociedade para que as crianças possam viver seus papéis ocupacionais de serem filhos, alunos e brincarem de maneira justa. 


\section{CONCLUSÃO}

A socialização entre o tema justiça ocupacional e interdisciplinaridade/ interprofissionalidade neste relato de experiência apontou para a ligação entre o trabalho interdisciplinar e a promoção de justiça ocupacional, trazendo para o cotidiano dos serviços em saúde mental a importância de se estruturar um acompanhamento integral, interprofissional e capaz de diminuir os estados de injustiças ocupacionais. O relato apontou para uma relação entre os estudos que abordam a justiça ocupacional e as ações promovidas em um CAPS Infanto Juvenil, demonstrando que uma equipe integrada tem potencial para desenvolver acompanhamentos co-construídos, críticos e promotores de empoderamento, e assim, podendo ser relacionado a promoção de justiça ocupacional. A partir desta vivência não é possível discorrer sobre haver uma estreita relação entre o trabalho interdisciplinar e o conceito de justiça ocupacional a nível nacional, porém, é possível responder que no âmbito do serviço de saúde mental acompanhado pode-se observar várias nuances que demonstraram a dependência da troca interdisciplinar para promoção de justiça ocupacional. Nota-se que ainda há poucas publicações no meio científico brasileiro sobre a justiça ocupacional, assim este relato também discorre sobre a importância de se buscar estudar e compreender mais o tema sob o contexto brasileiro no campo de estudos da terapia ocupacional. Por fim, entende-se que apesar de ser um tema estudado e defendido dentro dos processos da profissão terapia ocupacional é importante que seja promovido com a articulação entre diversas profissões, neste relato observou-se uma resposta positiva com a integração da terapia ocupacional com o serviço social, a psicologia e a farmácia.

\section{REFERÊNCIAS}

AMERICAN OCCUPATIONAL THERAPY ASSOCIATION. et al. Occupational therapy practice framework: domain and process. North Bethesda, 2020.

BRASIL. MINISTÉRIO DA SAÚDE. Lei nำ10.216, Lei da Reforma Psiquiátrica de 06 de abril de 2001. Diário Oficial da União. 
CÓRDOBA, A. G. Sobre as novas formas de colonização em terapia ocupacional. Reflexões sobre a ideia de Justiça Ocupacional na perspectiva de uma filosofia política crítica. Cadernos Brasileiros de Terapia Ocupacional, v. 28, p. 1365-1381, 2020.

CERVO, E. B. et al. Interprofissionalidade e saúde mental: uma revisão integrativa. Rev. Psicol Saúde e Debate, v. 6, n. 2, p. 260-272, 2020.

DUARTE, M. Q. et al. COVID-19 e os impactos na saúde mental: uma amostra do Rio Grande do Sul, Brasil. Ciência \& Saúde Coletiva, v. 25, p. 3401-3411, 2020.

HAMMELL, K. W. Ações nos determinantes sociais de saúde: avançando na equidade ocupacional e nos direitos ocupacionais. Cadernos Brasileiros de Terapia Ocupacional, v. 28, p. 378-400, 2020.

LIMA, T. C. S. et al. A documentação no cotidiano da intervenção dos assistentes sociais: algumas considerações acerca do diário de campo. Revista Textos \& Contextos, Porto Alegre, v. 6, n. 1, p. 93-104, jan-jun. 2007.

MATTOS, M. P. et al. Educação Permanente em Saúde nos Centros de Atenção Psicossocial: revisão integrativa da literatura. Saúde Debate, Rio de Janeiro, v. 44, n. 127, p. 1277-1299, out-dez. 2020.

MAROJA, M. C. S.; JÚNIOR, J. J. A.; NORONHA, C. A. Os desafios da formação problematizadora para profissionais de saúde em um programa de residência multiprofissional. Interface, Botucatu, 2020.

SILVA, C. A.; ARAUJO, M. D. Programa de Residência Multiprofissional em Saúde: o que mostram as publicações. Saúde Debate, Rio de Janeiro, v. 43, n. 123, p. 12401258, out-dez. 2019.

SILVA, J. R. et al. O "singular" do projeto terapêutico: (im)possibilidades de construções no CAPSi. Rev. Polis e Psique, 2019. 


\section{QUFN}

STADNYK, R.; TOWNSEND, E. A.; WILCOCK, A. Occupational justice. In: CHRISTIANSEN, C.; TOWNSEND, E. A. (Ed.). Introduction to occupation: the art and science of living. Englewood Cliffs, Prentice Hall, p. 329-358, 2010.

SY, M. P. et al. Occupational justice health questionnaire: reflections on its application. Cadernos Brasileiros de Terapia Ocupacional, v. 29, 2021.

TOWNSEND, E.; MARVAL, R. Profissionais podem realmente promover justiça ocupacional?. Cad. Ter. Ocup. UFSCar, São Carlos, v. 21, n. 2, p. 229-242, 2013. 